\title{
Polycystic kidney disease in children: a genetic and epidemiological study of 82 Finnish patients
}

\author{
HELENA KÄÄRIÄINEN \\ From the Department of Medical Genetics, University of Helsinki, and Department of Medical Genetic \\ Väestöliitto, Helsinki, Finland.
}

SUMMARY Information on 82 children in Finland, treated during the years 1974 to 1983 fọ polycystic kidney disease, was collected retrospectively. The occurrence was of the order of 1:8000 births. Fifty-one of the children had early lethal disease and 31 survived for over 28 days $\stackrel{\circ}{\circ}^{+}$

These children came from 69 families. They were divided by family studies into three groups? autosomal dominant polycystic kidney disease (DPKD) in 11 families, autosomal recessive polycystic kidney disease (RPKD) in 14 families, and sporadic cases in 44 families. In three of thE DPKD families there were two or more sibs with DPKD which manifested neonatally. The majority of the grandparents of the children with RPKD and sporadic polycystic kidney disease were born in the same sparsely populated areas in northern, central, and eastern Finland, whic suggests that most of the sporadic cases are also actually RPKD.

The purpose of this study was to find patients with polycystic kidney disease manifesting in childhood and to categorise them using genetic criteria. The observed series of cases geneticall classified as DPKD and RPKD will serve as a basis for the further aim of defining clinical criterio for the differential diagnosis of these two entities.

Polycystic kidney disease comprises two main clinical entities: autosomal dominant polycystic kidney disease (DPKD), which is also called adult polycystic kidney disease, and autosomal recessive polycystic kidney disease (RPKD), which is also called infantile polycystic kidney disease or polycystic kidney disease of childhood. As the adult disease may manifest in childhood and children with the infantile disease may survive into adulthood, it has been suggested that the disease entities should be called 'dominant' and 'recessive' instead of 'adult' and 'infantile'.' Various cystic conditions of the kidneys have erroneously been called 'polycystic', but the term should be used in a restricted sense, meaning only the two major types of heritable cystic disorder. $^{2}$

DPKD and RPKD differ from each other by their different modes of inheritance as is indicated by their names, but clinically they may resemble each other. There are no simple clinical or morphological definitions for these entities because the clinical picture of DPKD is highly variable and because

Received for publication 20 October 1986.

Revised version accepted for publication 5 January 1987.
RPKD seems to consist of two or more subtypes

DPKD usually manifests at the age of 30 to 40 years. The kidneys are enlarged and contain nume $\bar{B}$ ous roundish cysts of different sizes. The cysts afe mostly of tubular origin but they may originate from any part of the nephron. There may be cysts in the liver, especially in older patients. The presenting symptoms are usually haematuria, pain, or hypertension. There is slowly progressive renal insuffp ciency. Some members of the family possessing the gene may remain symptomless throughout life There are several reports of DPKD occurring if children, even newborns, but usually the symptoms are slight or absent in childhood. ${ }^{2}$

RPKD manifests neonatally or later in childhood The kidneys are large and filled with more or les fusiform cysts of tubular origin. The liver is always involved, with proliferation of intrahepatic bi ducts and periportal fibrosis. ${ }^{2}$ Symptoms vary from perinatal death of a baby with a Potter habitus t\$ृ renal insufficiency of variable progression in infanco or portal hypertension in later childhood. The earl lethal form of RPKD seems to be genetical distinct, ${ }^{2}$ but there is controversy over whether the 
milder forms are manifestations of a clinically wide spectrum of one disease ${ }^{14}$ or whether they can be further subdivided by clinical, genetic, and histological criteria. ${ }^{5}$

The overall incidence of polycystic kidney disease in childhood is not known. The frequency of RPKD in paediatric necropsy material varies from $1 \cdot 3 / 10^{3}$ to $5 \cdot 9 / 10^{3}$ childhood necropsies. ${ }^{6} 7$ There are no estimates of the number of surviving cases of RPKD or of childhood DPKD.

The purpose of this nationwide study was to collect all children with polycystic kidney disease from a 10 year period in order to discover the occurrence of the disease in Finnish children, to classify the patients by genetic criteria, and to investigate some of the genetic aspects of the disease.

\section{Patients and methods}

All children under 16 years of age treated for various cystic kidney diseases in Finland during 1974 to 1983 were collected retrospectively from three sources. (1) Children who had died with the diagnosis of any cystic kidney disease were sought from the data of the Central Statistical Office of Finland for the 10 year period concerned. (2) Surviving cases were collected from computerised diagnosis lists for the same 10 year period from all the five Finnish university hospitals except the University Hospital of Turku, where computerised listing was only started in 1977 . Cases with polycystic kidney disease, dysplastic and other cystic kidneys, various kidney malformations, hepatic cysts, hepatic fibrosis, or Banti disease were collected. (3) All families who had received genetic counselling for polycystic kidney disease at the Department of Medical Genetics in Väestöliitto during the time concerned were included. The Finnish Register of Congenital Malformations ${ }^{8}$ was also searched, but all the cases found there had already been found through some other source.

By this preliminary screening 286 children were found. Their hospital records were checked and 81 were considered to have polycystic kidney disease when using the following criteria.

(1) The patients had to have had at least ultrasound or computed tomography of the kidneys or a kidney biopsy or, if they died neonatally before such studies, a necropsy with both macroscopic and microscopic studies of the kidneys.

(2) The patients had to have at least one 'macroscopic' cyst in each kidney and more than one in one kidney detected by ultrasound or computed tomography or findings suggesting several 'micro- scopic' cysts in both kidneys found by ultrasound, computed tomography, or histological studies.

(3) The patients were not to have other urinary tract malformations, signs of any syndrome, or findings suggesting some other defined structural renal disease.

In addition, one infant, who had died neonatally, was included although necropsy was not performed. She had huge kidneys and died of respiratory insufficiency. The diagnosis was considered definite even without necropsy as her sister had died neonatally from polycystic kidney disease which was verified at necropsy. The diagnoses of the remaining 204 children are presented in the table.

The families of the children with polycystic kidney disease were approached differently depending on whether the proband had survived the neonatal period or not. If the child had survived, the parents were contacted through the paediatrician. Family histories were taken and, if positive, checked from hospital records. Ultrasound examination of the kidneys and liver was performed on parents and sibs. If the child had died neonatally, the parents and sibs were not contacted or studied. It was thought unethical to examine family members long after the death of the patient, as the possibility of finding a disease was considered to be very small, whereas the risk of arousing anxiety was high.

The number of sibs was checked from the population register. The cause of death for dead sibs was found through hospital records. The birthplaces of grandparents were checked from the population register to look for possible close consanguinity and to find out the geographical distribution of the birthplaces of the ancestors.

It was considered that there was DPKD in the family if one of the parents of the proband was affected and RPKD if there were at least two affected sibs and the parents were unaffected.

TABLE Diagnoses of the 204 children who were initially screened for the study but had a disease other than polycystic kidney disease

\begin{tabular}{ll}
\hline Diagnosis & No of patients \\
\hline Bilateral dysplastic kidneys & 46 \\
and perinatal death & 46 \\
Unilateral dysplastic kidney & 15 \\
Banti disease (without cystic kidneys) & 5 \\
Tuberous sclerosis & 6 \\
Meckel syndrome & 8 \\
Solitary kidney cyst & \\
'Nephronophthisis-like disease' with & \\
hepatic fibrosis resembling the patients & 1 \\
published by Bolchis et al' & \\
Various kidney and liver malformations. & 77 \\
$\quad$ unrecognised syndromes, etc. & \\
\hline
\end{tabular}


Family 1
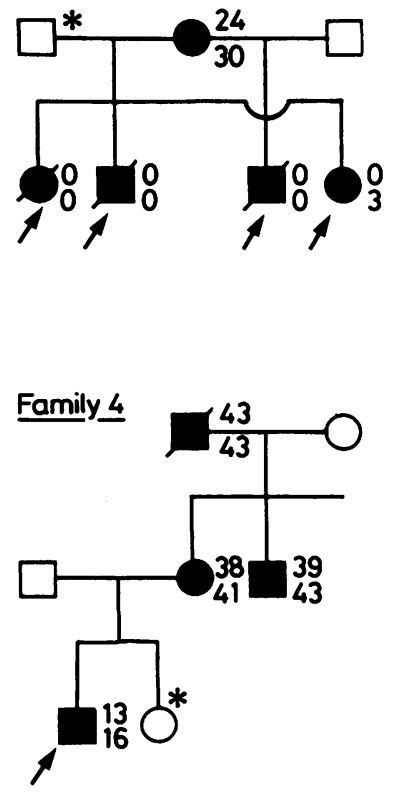

Family 7

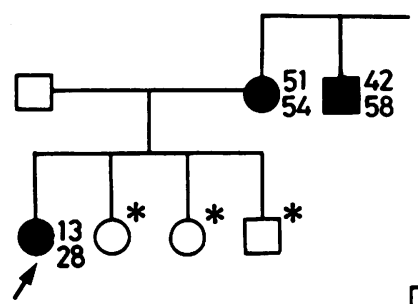

Family 2

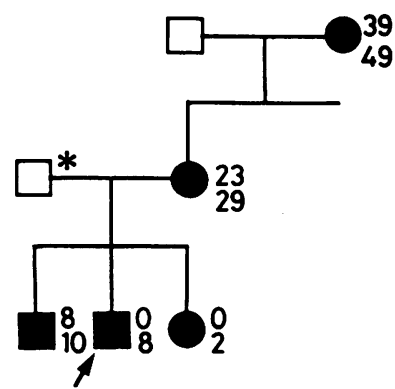

Family 5

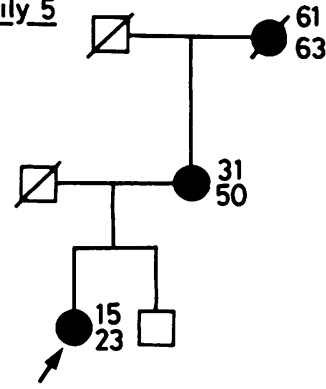

Family 8

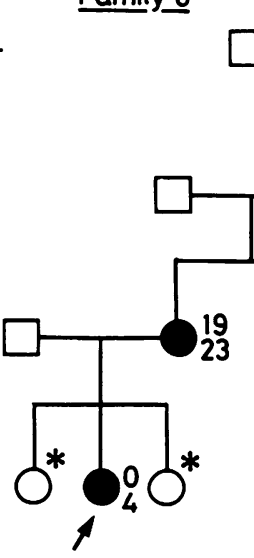

Family 3

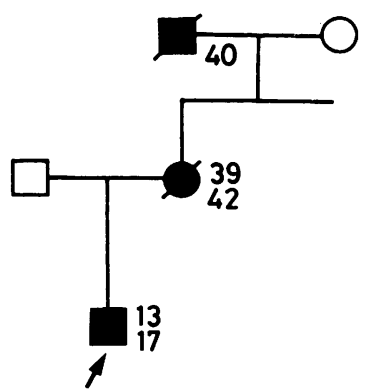

Family 6

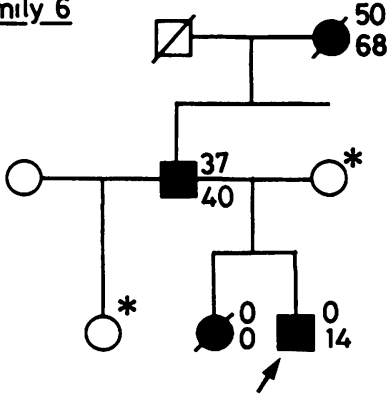

Family 9

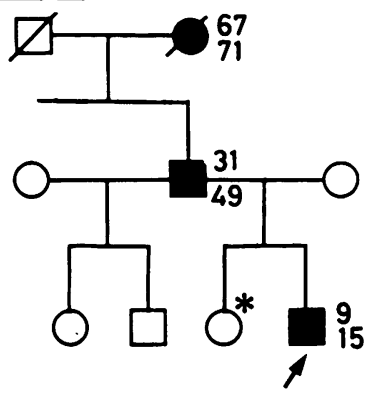

Family 10

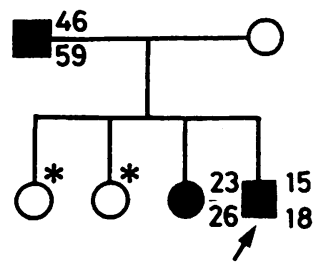

Family 11
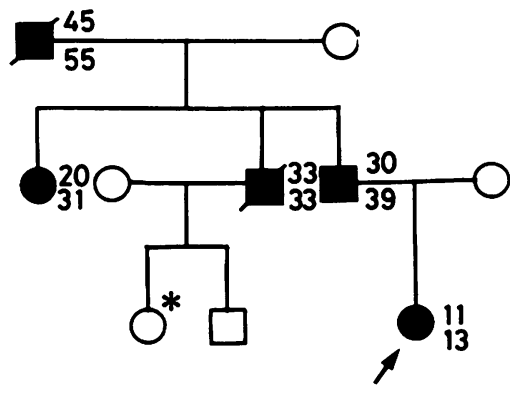

FIG 1 The pedigrees of the 11 families with DPKD. Affected males and females are marked by black squares and circles The upper number by each subject is the age (in vears) of the person at diagnosis and the lower number is the age at death or the present age of survival. o means neonatal. Healthy subjects who have had ultrasound, urography, or histological examinations to rule out polycystic kidneys are marked by an asterisk. 


\section{Results}

Of the 82 children with polycystic kidney disease, one was stillborn, 50 died neonatally, and 31 survived beyond the neonatal period. The cystic kidneys were noticed immediately after birth in 69 cases, at six weeks in one case, at six to eleven years in six cases, and at 13 to 15 years in six cases. All the patients were found independently of their affected sibs or parents and are thus index cases in this study. They came from 69 families.

The parents were contacted in 30 families where at least one proband had survived beyond the neonatal period. The kidneys of 41 parents were studied by ultrasound and four parents by intravenous pyelography. No studies were done on six parents, who had already had DPKD diagnosed, and on eight parents the spouses of whom had had DPKD diagnosed. One father refused to be examined. There were 35 probands in these 30 families, and they had 41 full sibs and three half sibs from another marriage of the affected parent. In addition to the probands, three sibs had already had polycystic kidney disease diagnosed but they had been treated before or after the period of this study. Of the remaining sibs, 31 were studied by ultrasound,
Family 12

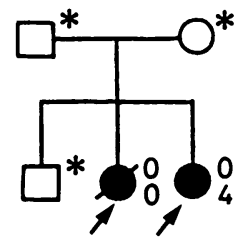

Family 15

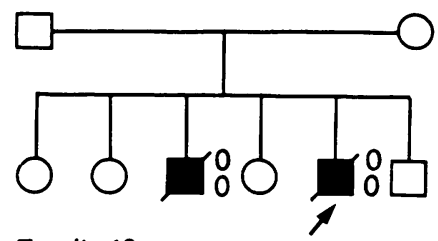

Family 18

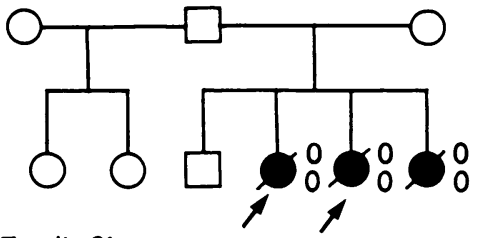

Family 21

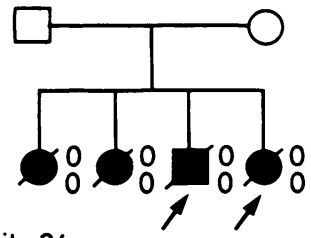

Family 24

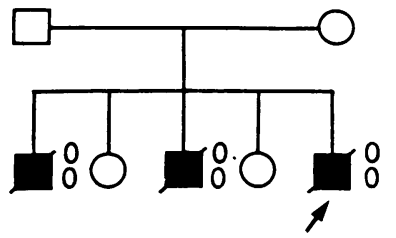

Family 13

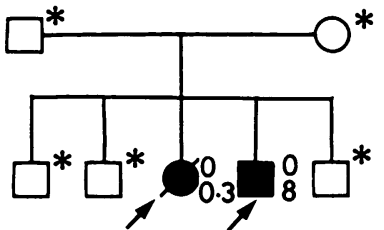

Family 16

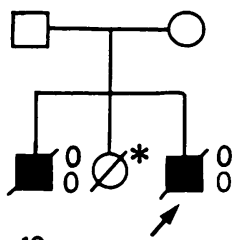

Family 19

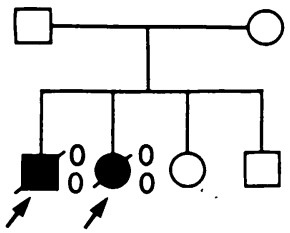

Family 22

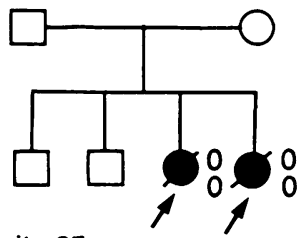

Family 25

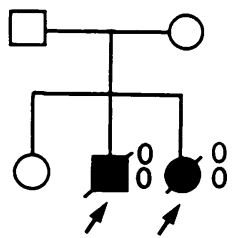

Family 14

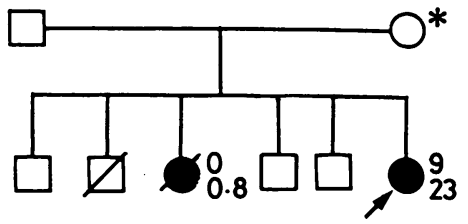

Family 17

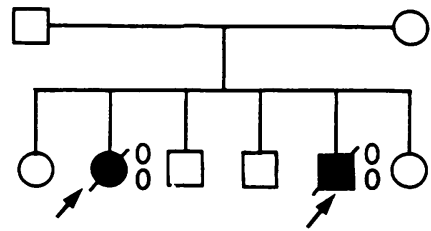

Family 20

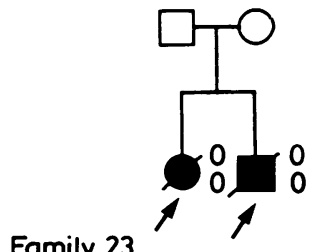

Family 23

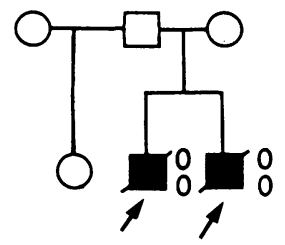

FIG 2 The pedigrees of the 14 families with RPKD. For symbols see fig 1 . 
one by intravenous pyelography, seven refused to be examined, and two had been stillborn.

The 39 families where all the probands had died neonatally were not contacted. Through the population register it was found that the 47 probands in these families had 56 full sibs, nine of whom had died neonatally. Of these, seven had had polycystic kidney disease confirmed at necropsy. Two had died with respiratory difficulties and necropsy was not performed.

The family studies gave the following results. There was DPKD in 11 families. The affected parent was the mother in seven families and the father in four families. The affected parents in these 11 families had 31 children, of whom 18 were affected,
10 were normal by ultrasound, and three were not. studied. The pedigrees of these 11 families are shown in fig 1 including the age of every affecte $\Phi$ person at diagnosis and at death or at the time of this study.

There was RPKD that was not neonatally lethal i three families. The kidneys of the parents at 35 to 52 years of age were normal by ultrasound. There were 13 full sibs altogether and two were affected in eact sibship. Altogether six were affected, four had normal kidneys by ultrasound, and three were now studied. One sib was stillborn; enlarged kidneys. were not mentioned in the hospital records an $\Phi$ necropsy was not performed.

There was neonatally lethal familially occurrinio
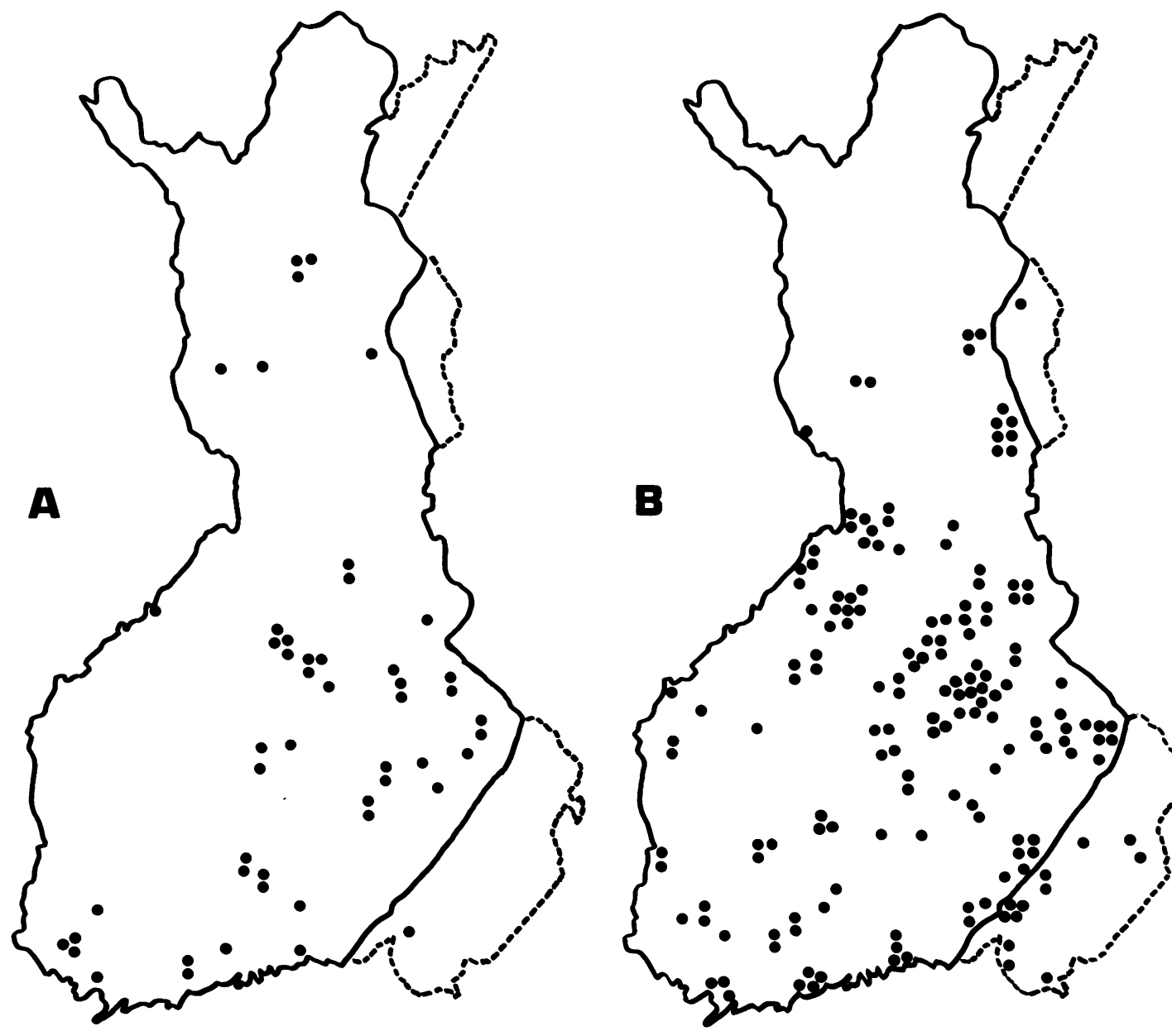

FIG 3 The birthplaces of grandparents of the patients with RPKD $(A)$ and of the sporadic patients $(B)$. One dot marks the birthplace of one grandparent. The area limited by the broken line belonged to Finland before the second world war. 
polycystic kidney disease which was considered to be RPKD, though the parents were not studied, in 11 families. There were 43 full sibs altogether. Of them, 26 had been affected, at least two in each sibship. The remaining 17 were alive but polycystic kidneys had not been ruled out by ultrasound.

The pedigrees of the 14 families with RPKD and the age of each patient at diagnosis and at death or at the time of this study are shown in fig 2 .

There were 44 sporadic cases. The parents of the 16 probands who had survived the neonatal period were studied and found to be normal. Of the 35 full sibs in these families, the 16 probands were affected, 17 were normal by ultrasound, one was stillborn with normal kidneys at necropsy, and one was not studied. The parents and sibs of the 28 probands who had died neonatally were not studied. There were 60 full sibs altogether in these families. Of them, the 28 probands had been affected. Two more had died neonatally, but necropsies had not been performed and as the clinical information was scanty, it is impossible to judge whether these two had polycystic kidneys or not. The remaining 30 were alive but polycystic kidneys were not ruled out.

The sex ratio of the children affected by DPKD was 1 , of the children affected by RPKD $0 \cdot 88$, and of the sporadic cases 1.1 .

The ancestors were traced back only as far as grandparents. No consanguineous marriages were found. The mother of one sporadic proband was the first cousin of the father of four affected sibs. The nephew of the mother of another sporadic proband had an affected child, born after this study. In both kindreds all patients had died neonatally. The geographical distribution of the birthplaces of the grandparents of the probands in 14 families with RPKD and of the 44 sporadic cases are shown in fig 3.

\section{Discussion}

A total of 82 children with polycystic kidney disease was found retrospectively during the years 1974 to 1983 in Finland. The dead cases were all found from the data of the Central Statistical Office of Finland, where the cause of death is compulsorily registered. As cystic kidneys can hardly be overlooked at necropsy, only those cases in which necropsy had not been performed could have been missed through this source. From the data of the Central Statistical Office of Finland it can be estimated that at least $80 \%$ of stillborn infants or those who had died in the neonatal period had had necropsies during 1974 to 1983.

The surviving cases were sought from university hospitals only. It was assumed that children with such a rare and often serious disease were, as a rule, referred to a university clinic. However, one mild case that had been treated only at a district hospital was found from the Department of Medical Genetics at Väestöliitto.

The criteria for polycystic kidney disease were chosen in order to find all the children who had been treated for either DPKD or RPKD. When collecting patients with RPKD, Lieberman et al ${ }^{4}$ considered enlargement of the kidneys and liver to be an obligatory finding. This was not suitable for the purpose of the present study, as children with DPKD have a normal liver and in the early phase of the disease the kidneys are also of normal size. Blyth and Ockenden ${ }^{5}$ included in their material only cases with histological verification of the diagnosis. Nowadays, histological studies are performed less frequently as imaging techniques have developed, and thus patients with kidney cysts verified only by ultrasound or computed tomography were included in our study. However, children with cystic dysplastic kidneys might have been erroneously included. Bear et $a l^{10}$ regarded one cyst in each kidney and more than one in one kidney as minimal criteria for diagnosing DPKD in asymptomatic members of affected kindreds. His criteria were used in this study, but without the need for a positive family history, because cysts in the kidneys of healthy children are rare $^{11}$ and even a few cysts suggest polycystic kidney disease in childhood. However, early cases of DPKD with only one or two kidney cysts would have been missed. Moreover, as most children with DPKD are totally asymptomatic ${ }^{12} 13$ there must be many children with DPKD who have never been treated and thus were not found.

During 1974 to 1983 the total number of births in Finland was 650827 . Thus 1 in 7937 births was found to have polycystic kidney disease. This is not an accurate way to express the occurrence of the disease because many of the probands were born before the study period and because some children born during that period may have their disease diagnosed many years later.

There are no comparable estimates of occurrence of polycystic kidney disease in childhood. Early estimates of the incidence of 'polycystic kidneys' in children were based on paediatric necropsy material and mixed with cases that would now be called 'dysplastic' or 'multicystic' instead of 'polycystic', as well as syndromic cases. ${ }^{14}{ }^{15}$ Even a recent study of 'polycystic kidneys' from the Hungarian Congenital Malformation Registry for the years 1970 to $1978^{16}$ included all polycystic kidneys of Potter types I and II; the latter should be called dysplastic cystic kidneys. ${ }^{17} 18$ Therefore it is difficult to compare 
their figure of $0 \cdot 11 / 10^{3}$ births with the present material. If only the cases diagnosed during the first year of life are counted, and if the children with dysplastic cystic kidneys found in the course of this study are added, a figure of $0 \cdot 18 / 10^{3}$ is achieved. Though this figure is higher than that of the Hungarian Congenital Malformation Registry, it may only reflect different methods of collecting the material and not any true difference in incidence.

The incidence in the paediatric necropsy material in North Finland ${ }^{7}$ was higher than in a similar study from France ${ }^{6}$ but this evidently represents a local cluster in North Finland (fig 3). There are no estimates of the number of children with polycystic kidney disease who survive and from published reports one gets the impression that these patients are not extremely rare anywhere. ${ }^{45}{ }^{19}$ It seems that no form of the disease is exceptionally common in Finland. Thus polycystic kidney disease does not belong to the group of monogenic diseases overrepresented in Finland called 'the Finnish disease heritage'.

The disease was interpreted as being DPKD in families 1 to 11 (fig 1). The proportion of affected sibs in these families was 0.58 , which is higher than expected as some of the children may still manifest the disease. It has been estimated that only $66 \%$ of those affected by DPKD can be diagnosed by ultrasound by 15 years of age. ${ }^{10}$ Among the sibs found to be normal, four were still under 15 years of age. The high proportion of those affected and manifesting the disease in childhood is due to ascertainment as the study originated from affected children, not affected parents.

DPKD manifested neonatally in nine children from four families (fig 1). At least 30 such families have been reported before. ${ }^{50-39}$ In eight families (families 1,2, and 6 in this series and five families previously published ${ }^{527} 283035$ ), DPKD manifested neonatally in more than one sib. As the disease was not exceptionally early or severe in the affected parent or other relatives, there was apparently nothing exceptional in the gene itself. The affected parent was the mother in 19 and the father in 15 families; thus the sex of the affected parent did not seem to influence the early manifestation. The four children with neonatal DPKD in family 1 (fig 1) had two different fathers, which is not in keeping with the idea of some effect of the allele from the unaffected parent. Whatever the cause for the early onset of DPKD, the risk of recurrence of that type in a sibship seems to be higher than would be expected.

The disease was interpreted to be RPKD in families 12 to 25 (fig 2). In families 15 to 25 the parents were not studied but the inheritance was assumed to be recessive, as it was considered highl unlikely that DPKD would manifest in its vere unusual form, a neonatally lethal disease, in a廿 affected sibs. Nevertheless, this had been the situation in family 1 before the birth of the younges child who survived and is now three years old. Thu盘 families with neonatally lethal polycystic kidne disease should not automatically be assumed to be RPKD, but instead it would be wise to examine the kidneys of the parents by ultrasound to exclude the possibility of DPKD, at least if careful histologica出 studies have not been performed. The clinicats picture was highly variable in families 12 to 14 buff very uniform in families 15 to 25 , which supports th assertion $^{14}$ that the early lethal or 'perinatal' forrip of RPKD is a genetically separate entity, but mildew forms cannot be further classified by clinical cours 苍 as they seem to vary intrafamilially.

Family studies of the early lethal form of infantil $\overrightarrow{\vec{e}}$ polycystic kidney disease have suggested autosomat recessive inheritance, but the material has bee small. ${ }^{15}{ }^{40}$ No family studies have been performed to confirm the mode of inheritance in milder form $\vec{\Phi}$ of RPKD, but recessive inheritance has bee⿳亠丷⿵冂卄 assumed as there are several examples of typicab recessive families. In this study there were 14 typica $\$$ recessive families with at least two affected sibs an unaffected parents. The proportion of affected sib can be calculated only after the sporadic cases have been classified as DPKD or RPKD by morpho logical, imaging, or other clinical criteria.

The sex ratio in DPKD, RPKD, and in the sporadic cases was very close to 1 , as expected i autosomal inheritance.

Fig 3 shows the geographical distribution of the birthplaces of the grandparents of the children witf RPKD and of the sporadic cases. These maps resemble each other closely. They also resemble the corresponding maps of some of the 20 rare recessive disorders overrepresented in Finland. ${ }^{41}$ It is typical of these maps that most of the ancestors of the patients came from the sparsely populated areas it the northern, central, and eastern parts of Finlane that were permanently settled as late as the 16 th century. This could mean that most sporadic cases actually do have RPKD and that the frequency o中 the recessive gene (genes) is so low that regionat isolates are often needed before homozygotes appear.

Detailed studies of the present material are i⿱一⿻丿口乚 progress. The classification of the material primarilis by genetic criteria is serving as the basis for defining other criteria, clinical, imaging, and histological, ho which any sporadic case can be reliably classifie At this point it seems that almost all of the sporad cases in this study actually have RPKD. 
I wish to thank the Central Statistical Office of Finland, the Finnish Register of Congenital Malformations, and the five University Hospitals in Finland for help in collecting the patients. This work was supported by grants from three Finnish foundations: the Foundation for Pediatric Research, the Kidney Foundation, and the Paulo Foundation.

\section{References}

I Stickler GB, Neel IV, Baggenstoss AH, Bernstcin J. Polycystic kidney disease in infants. Proceedings of the VIth international symposium of pediatric nephrology. Hannover, 1983. In: Brodehl J, Ehrich JHH, eds. Pediatric nephrology. Berlin: Springer-Verlag, 1983:363-7.

2 Bernstein J. Polycystic disease. In: Edelman CM. ed. Pediatric kidney disease. Boston: Little, Brown and Co, 1978:557-70.

3 Dalgaard OZ. Bilateral polycystic disease of the kidncys. A follow-up of two hundred and eighty-four patients and their families. Acta Med Scand 1957:328(suppl 158):13-255.

4 Lieberman E. Salinas-Madrigal L, Gwinn JL. Brennan LP. Fine RN, Landing BH. Infantile polycystic disease of the kidneys and liver: clinical, pathological and radiological correlations and comparison with congenital hepatic fibrosis. Medicine (Baltimore) 1971:50:277-318.

5 Blyth H. Ockenden BG. Polycystic disease of kidneys and liver presenting in childhood. J Med Genet 1971;8:257-84.

6 Larroche JC. Developmental pathology of the neonate. Amsterdam: Excerpta Medica, 1977:96-7.

7 Uhari M. Herva R. Polycystic kidney disease of perinatal type. Acta Paediatr Scand 1979;68:443-4.

* Saxén L. Twenty years of study of the etiology of congenital malformations in Finland. In: Kalter $\mathrm{H}$, ed. Issues and reviews in teratology. Vol 1. New York: Plenum Press, 1983:73-110.

"Boichis H. Passwell J. David R. Miller H. Congenital hepatic fibrosis and nephronophthisis. $Q J$ Med 1973:42:221-33.

10 Bear JC, McManamon P. Morgan J, et al. Age at clinical onset and at ultrasonographic detection of adult polycystic kidncy diseasc: data for genetic counseling. Am J Med Genet 1984;18: 45-53.

1 Tada S, Yamagishi J, Kobayashi H. Hata Y. Kobari T. The incidence of simple renal cysts by computed tomography. Clin Radiol 1983:34:437-9.

12 Gabow PA. Iklé DW. Holmes JH. Polycystic kidncy discase: prospective analysis of nonatzotemic patients and family members. Ann Intern Med 1984:101:238-47.

13 Churchill DN, Bear JC. Morgan J. Payne RH. McManamon P. Gault MH. Prognosis of adult onset polycystic kidney discase reevaluated. Kidney Int 1984:26:190-3.

14 Bardram E. Congenital kidney malformations and oligohydramnios. Acta Obstet Gynaecol Scand 1930:10:134-59.

15 Lundin PM. Olow I. Polycystic kidneys in newborns. infants and children. A clinical and pathological study. Acta Paediatr Scand 1961;50:185-200.

16 Rutkai K. Czeizel A. Obstetric features of mothers giving birth to infants with polycystic discase of the kidneys. Arch Gynecol 1982:231:241-5.

17 Osathanondh V. Potter EL. Pathogenesis of polycystic kidneys. Type I due to hyperplasia of interstitial portions of collective tubules. Type II duc to inhibition of ampullary activity. Arch Pathol 1964:77:466-84.

is Bernstein J. Kissane M. Hereditary disorders of the kidney. In: Rosenberg HS, Bolande RP. eds. Perspectives in pediatric pathology. Vol 1. Chicago: Year Book Medical Publishers. 1973:117-46.

19 Chilton SJ. Cremin BJ. The spectrum of polycystic discase in children. Pediatr Radiol 1981:11:9-15

2" Mchrizi A. Kosenstein BJ. Pusch A. Askin JA. Taussing HB.
Myocardial infarction and endocardial fibroclastosis in children with polycystic kidneys. Bull Johns Hopkins Hosp 1964;115: 92-8.

2 Kaye C, Lewy PR. Congenital appearance of adult type (autosomal dominant) polycystic kidney diseasc. $J$ Pediatr 1974:85:807-10.

22 Bengtsson U, Hedman L, Svalander C. Adult type of polycystic kidney disease in a newborn child. Acta Med Scand 1975:197: 447-50.

23 Ross DG. Travers $H$. Infantile presentation of adult-type polycystic kidney disease in a large kindred. J Pediatr 1975; 87:760-2.

24 Stickler GB. Kelalis PP. Polycystic kidney diseasc. Recognition of the "adult form" (autosomal dominant) in infancy. Mavo Clin Proc 1975:50:547-8.

25 Fellows RA. Leonidas JC. Beatty EC Jr. Radiologic features of "adult type" polycystic kidney disease in the nconatc. Pediatr Radiol 1976:4:87-92.

26 Begleiter ML. Smith TH, Harris DJ. Ultrasound for genetic counselling in polycystic kidney disease. Lancet 1977;ii:1073-4.

27 Loh JP. Haller JO, Kassner EG, Aloni A, Glassberg K. Dominantly-inherited polycystic kidncys in infants: association with hypertrophic pyloric stenosis. Pediatr Radiol 1977:6:27-31.

28 Eulderink F. Hogewind BL. Renal cysts in premature children: occurrence in a family with polycystic kidncy disease. Arch Pathol Lab Med 1978;102:592-5.

29 Shokeir MHK. Expression of "adult" polycystic renal discase in the fetus and new-born. Clin Genet 1978:14:61-72.

3) Fryns JP, Van Den Berghe H. "Adult" form of polycystic kidney disease in neonates. Clin Genet 1979:15:205-6.

3 Mclean RH, Goldstein G. Conard FU, Rasoulpour M, Crawford B. Autosomal dominant (adult) polycystic kidncy disease in childhood. Conn Med 1980;44:690-2.

32 Chevalier RL. Garland TA. Buschi AJ. The neonate with adulttype autosomal dominant polycystic kidney disease. Int J Pediatr Nephrol $1981 ; 2: 73-7$.

33 Freycon MT, Boyer C. Lauras B. Annino R. Freycon F. Reins polykystiques a transmission dominante chez un nourisson. Pediatrie 1982:37:287-94.

i4 Garel L, Sauvegrain J, Filiatrault D. Polykystose dominante chez un nouveau-né. Ann Radiol 1983;26:183-6.

35 Proesmans W, Van Damme B. Casacr P. Marchal G. Autosomal dominant polycystic kidncy disease in the neonatal period: association with a cerebral arteriovenous malformation. Pediatrics 1982:70:971-5.

36 Zerres K. Weiss H, Bulla M. Roth B. Prenatal diagnosis of an carly manifestation of autosomal dominant adult-type polycystic kidney disease. Lancet 1982;ii:988.

37 Main D. Mennuti M. Cornfeld D. Coleman B. Prenatal diagnosis of adult polycystic kidncy discasc. Lancet 1983:ii: 337-8.

${ }^{3 \times}$ Farrel TP. Boal DK. Wood BP. Dagen JE, Rabinowitz R. Unilateral abdominal mass: an unusual presentation of autosomal dominant polycystic kidney disease in children. Pediatr Radiol 1984:14:349-52.

39 Hayden CK. Swischuk LE. Davis M. Brouhard BH. Puddling: a distinguishing feature of adult polycystic kidrey disease in the neonate. $A J R$ 1984:142:811-2.

+1 Heggö O. Natvig JB. Cystic disease of the kidneys. Autopsy report and family study. Acta Pathol Microbiol Scand 1965:64 459-69.

41 Norio R. Diseases of Finland and Scandinavia. In: Rothschild H. ed. Biocultural aspects of disease. New York: Academic Press, 1981:359-415.

Correspondence and requests for reprints to $\mathrm{Dr}$ Helena Kääriäinen, Department of Medical Genetics, University of Helsinki, Haartmaninkatu 3, 00290 Helsinki, Finland. 